\title{
Rail Names as Indicators of Enduring Influence of Old Provinces in Modern Japan
}

\author{
Loren SIEBERT \\ Department of Geography and Planning, University of Akron, \\ Akron, OH 44325-5005, USA
}

\begin{abstract}
Japan's ancient provinces were converted into modern prefectures after the Meiji Restoration of 1868. In the Kanto region, the eight former provinces of Musashi, Sagami, Awa, Kazusa, Shimosa, Hitachi, Shimotsuke, and Kozuke were reorganized into the seven prefectures of Tokyo, Saitama, Kanagawa, Chiba, Ibaraki, Tochigi, and Gunma. At the same time, railroads were being built to provide a new transportation method linking geographic areas.

To what extent and how rapidly did the new prefectures replace the old provinces in geographic perception? One measure of that acceptance is how the new prefectures influenced the names given to rail companies, lines, and stations, all of which were created after the province system was replaced.

Mapping and categorizing of rail names from 1872 to 1995 shows that province-based names significantly outnumbered prefecture-based names. This is especially true for station names, but is strongly apparent for rail company and line names as well. For line names, provincebased names have outnumbered prefecture-related names throughout the period. Only in the case of company names has the number of prefecture-related names (including those based on a capital city with the same name as the prefecture) finally exceeded the number of provincebased names. Spatially, province-based company, line, and station names are spread extensively throughout most of the Kanto region, whereas prefecture/capital-based names are found primarily in and around Tokyo itself.

These temporal and spatial patterns reveal that the provinces have lived on in geographic perception long after their official demise.
\end{abstract}

Key words: rail names, province names, prefecture names, capital city names, toponyms, Japan, Kanto, Tokyo, political reorganization

\section{Introduction}

It is common for countries to be divided into smaller geographic areas, such as states, provinces, departments, prefectures, districts, or republics. In federal or confederated systems, these areas are semiautonomous political entities that existed before the country as a whole or that otherwise have considerable residual powers. In centralized systems, the areas normally are created by and exist at the mercy of the national government.

In the latter case, it is relatively easy for the national government to reorganize the divisions, changing their names and their boundaries, and even eliminating old ones and creating new ones. In Japan, a major reorgani- zation from provinces into prefectures occurred in the late $1800 \mathrm{~s}$, when the country was transformed from the semicentralized feudalism of the Tokugawa government into a modern centralized nation-state after the Meiji Restoration of 1868.

For Japanese living in the year 2000, thinking in terms of prefectures rather than provinces is as natural as thinking in terms of states rather than colonies and territories is for Americans. However, one hundred years ago in Japan, the prefecture system was just being finalized and memory of the province system was still fresh. My purpose in this paper is to evaluate whether the new prefectures quickly and completely replaced the provinces in Japanese geographic perception and association, or whether the provinces continued to play an 
important role well beyond their official demise.

To do so, I will look at the relationships between the province and prefecture geographic units and the naming of railroad companies, lines, and stations. Railroads were first built in Japan at the same time as the conversion from provinces to prefectures. The first line was completed in 1872 connecting the city of Tokyo with the port town of Yokohama to the south, and was later extended to the southwest along the Tokaido coastal region. Later, other lines opened heading outward in many other directions from Tokyo. Because railroads link geographic places and regions, the names adopted by the railroads may serve as a measure of quick acceptance of the new prefectures or, conversely, of an enduring affinity for the former provinces.

\section{Conversion from Provinces to Prefectures in the Kanto Region}

The new system of political divisions called prefectures (ken) replaced the overlapping, millennium-old province (kuni) system and centuries-old feudal domain (han) system (Papinot 1910). The conversion process began in 1868 and was substantially completed by 1888 , when the number of ken was stabilized at 47 (Ikegami et al. 1993). Some additional boundary changes occurred in the 1890s and later.

The Kanto region, centered around Tokyo, includes the largest flatland area of Japan-the Kanto Plain-and now contains one of the world's largest metropolitan areas and most extensive metropolitan rail transportation systems. Historically, eight provinces existed in this area: Musashi, Sagami, Awa, Kazusa, Shimosa, Hitachi, Shimotsuke, and Kozuke. In a multistage process during the last three decades of the $1800 \mathrm{~s}$, these eight provinces were converted into seven prefectures: Tokyo, Saitama, Kanagawa, Chiba, Ibaraki, Tochigi, and Gunma (also transliterated as Gumma).

Although the number of Kanto prefectures was set in 1888 , the overall borders were not finalized until 1893, when Kanagawa's northern area became the western part of Tokyo prefecture (a few minor changes were made later).
Kanto provinces in 1868 and prefectures in 1893 are shown in Figure 1 (with framed labels): (1) Kozuke province became Gunma prefecture, (2) Shimotsuke province became Tochigi prefecture, (3) Hitachi province and northern Shimosa province became Ibaraki prefecture, (4) the main part of Shimosa province and all of Kazusa and Awa provinces became Chiba prefecture, (5) Musashi province was split to form Saitama prefecture, Tokyo prefecture, and the northeastern part of Kanagawa prefecture, and (6) Sagami province and the above small section of Musashi province became Kanagawa prefecture.

From the standpoint of spatial continuity, in the Kanto region there are only two prefectures (Tochigi and Gunma) that coincide geographically with former provinces (Shimotsuke and Kozuke). Ibaraki prefecture is somewhat larger than Hitachi province. Chiba prefecture combines all or parts of three provinces (Awa, Kazusa, and Shimosa). Kanagawa is larger than Sagami province, having acquired the southeastern tip of Musashi. Finally, both Saitama and Tokyo prefectures are smaller than their predecessor province (Musashi).

From the standpoint of toponymic continuity, none of the current Kanto prefectures has maintained a former province name. Thus, not only are there major boundary changes, there also are completely new prefecture names. How did these significant differences between the province/prefecture names and boundaries impact the naming of rail companies, lines, and stations?

\section{Nature of Japanese Province, Prefecture, and Rail Names}

The purpose of a railroad is to connect one place with another place, so it is common for names of railroad companies and lines to reflect the names of the geographic areas served. This can be done by describing the region served (e.g., Illinois Central), a beginning point and region served (e.g., Norfolk and Southern), or points along the route (e.g., Atchison, Topeka, and Santa $\mathrm{Fe}$ ).

Similarly, Japanese rail names usually reflect the places served. Company and line names 


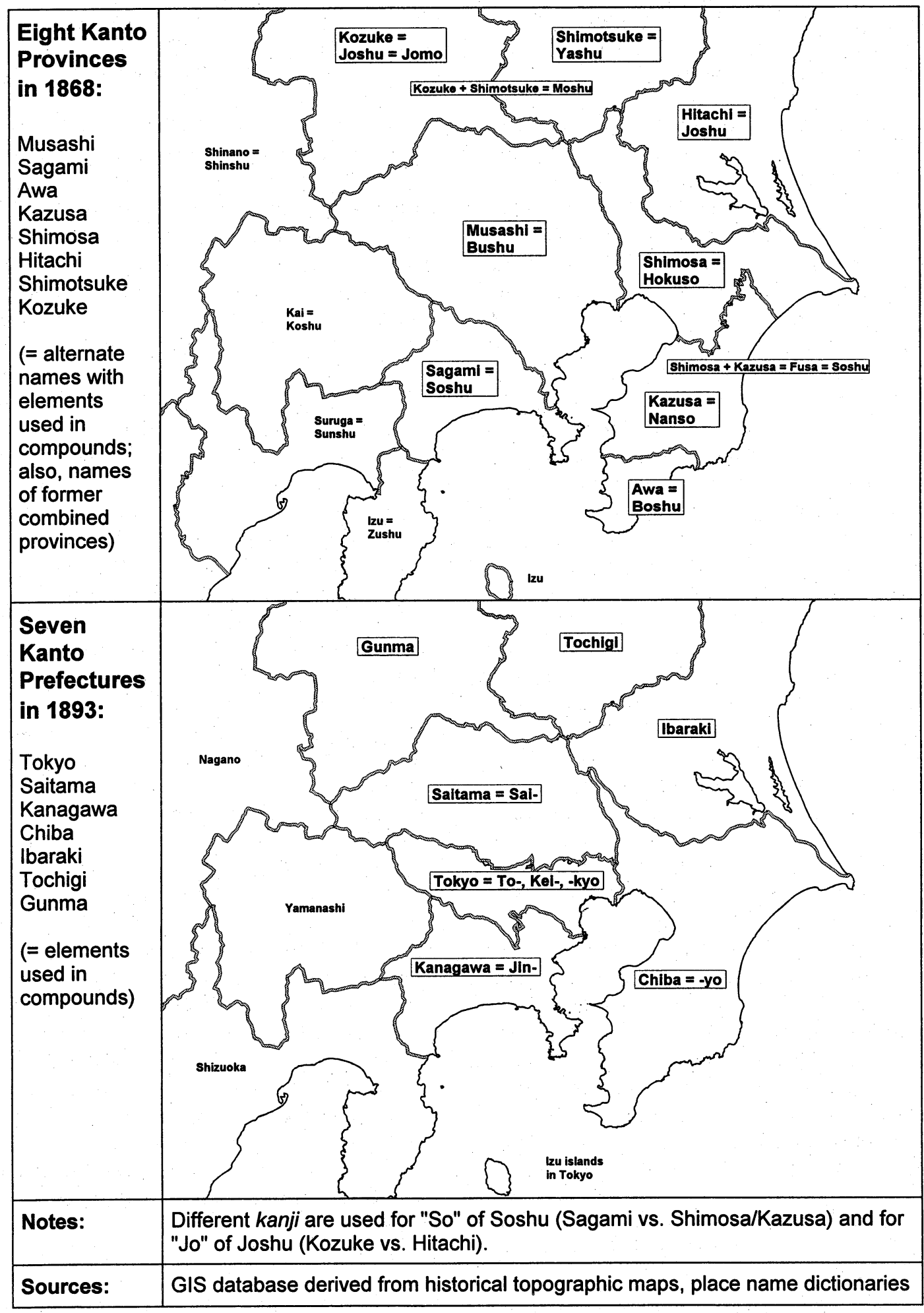

Figure 1. Kanto provinces in 1868 vs. final prefectures in 1893. 
may be based on larger areas (provinces or prefectures) or cities. Station names may be based on smaller areas (cities, towns, villages, or their subareas), nearby facilities (parks, temples, shrines, schools, etc.), or physical geographic features (rivers, lakes, hills, mountains, etc.). Some station names contain the name of a larger area to help differentiate two similar names. For example, when a station opened in Matsuyama town on the Tojo line in Saitama prefecture in 1923, it was named BushuMatsuyama, indicating its location in the former province Musashi (also called Bushu). It was thereby differentiated from other areas called Matsuyama ("Pine Mountain"), including an existing city on the island of Shikoku. When the town of Matsuyama merged with surrounding villages to become a city in 1954, the city used the name Higashi-Matsuyama to differentiate it from Matsuyama city in Shikoku, and the station name was then changed from Bushu- to Higashi-Matsuyama.

This use of compound names for cities and stations results from two factors. First, no two Japanese cities are allowed to have the same written name. Second, it has also been common to avoid duplication of rail station names. Besides using prefixes based on former provinces or directions (as in the example above), another common method of making station names unique is to use the company name as a prefix, especially to differentiate private from national line stations (e.g., Seibu-Shinjuku vs. Shinjuku).

In English, multi-word company names are often abbreviated by using the first letter of each word. For example, the Burlington Northern railroad is shortened to $\mathrm{BN}$, and now the Burlington Northern Santa Fe railroad to BNSF. This is possible because written English is an alphabetic language, with individual sounds represented by individual letters. The disadvantage is that such abbreviations often do not have a corresponding word-like pronunciation, so must often be pronounced as individual letters. Furthermore, they do not immediately convey the identities of the geographic areas served.

In contrast, Japanese is a syllabic language, where the smallest written unit is the syllable rather than an individual sound. The written unit is a single syllable when the kana scripts are used, or a single- or multi-syllable meaning unit when the Chinese-based kanji characters are used.

Instead of taking the first letter of each word to form an abbreviation, an entire syllable or meaning unit of each word is used. Such abbreviations always have a corresponding word-like pronunciation and usually provide a clear indication of the meaning as well. A train line connecting the cities of Tokyo and Yokohama could be called the Toyoko line-indeed, there is such a line. It combines the first meaning unit of Tokyo (to means "east") and the first meaning unit of Yokohama (yoko means "beside"). The resulting rail line name clearly and concisely indicates that the line connects Tokyo and Yokohama. The name derives its meaning from the original full words rather than from the components (i.e., the concept is "Tokyo-Yokohama" rather than "east-beside").

The situation is made more complex-and enriched-by the fact that the Japanese language often has at least two pronunciations for the Chinese kanji characters used in written Japanese: a Japanese pronunciation (called the kun-yomi) and a Sino-Japanese pronunciation (called the on-yomi). To form rail name compounds, usually the on-yomi of one of the kanji for a city or region is combined with the onyomi of one of the kanji for another city or region (e.g., Saikyo, from Saitama and Tokyo). Sometimes there is a mixture (e.g., Toyoko, consisting of an on-yomi unit from Tokyo and a kun-yomi unit from Yokohama).

This complexity and variety occurs in province names themselves, with each having a Japanese (kun-yomi) name and one or more SinoJapanese (on-yomi) variations. The latter often take one on-yomi unit from the province name and combine it with the on-yomi word shu ("province"). Thus, as shown in Figure 1 and Table 1, Musashi province was also known as Bushu, Sagami as Soshu, Awa as Boshu, Kazusa and Shimosa as Soshu (see next paragraph), Hitachi as Joshu, Shimotsuke as Yashu, and Kozuke as Joshu. Note that the kanji used for the two types of Soshu and two types of Joshu are different.

Even greater flexibility and complexity is 
brought about by the fact that during the lengthy history of provinces in Japan, the provinces were sometimes reorganized or renamed. For example, Kazusa and Shimosa initially were combined as Fusa province. Kazusa means "Upper Fusa" (Kami-Fusa was shortened and modified into Kazusa), and Shimosa means "Lower Fusa" (Shimo-Fusa was shortened to Shimosa). Kazusa was closer to the capital Kyoto, so it was called upper, whereas Shimosa was further, so was called lower (Shogakukan 1996). The province name Fusa is a kun-yomi, with so as its on-yomi (hence Soshu). Kazusa was also known as Nanso (South Fusa), whereas Shimosa was also known as Hokuso (North Fusa). This so is frequently used in rail company and line names based on Kazusa and/or Shimosa (Boso, Sobu, Hokuso, Joso). It is impossible to tell from the name alone whether these names represent Kazusa or Shimosa or both (except for Hokuso). I have therefore simply treated them as Fusa in Table 1.

A similar history exists for Kozuke and Shimotsuke. They were originally part of the province Kenu-no-kuni (no means "of" and kuni means "province"). Kami-Tsukenu was closer to the capital Kyoto, and Shimo-Tsukenu was further, hence the different names when the province was split (Shogakukan 1996). Over time, the names were modified and shortened to Kozuke and Shimotsuke. Alternative names are Joshu for Kozuke and Yashu for Shimotsuke. The term mo (an on-yomi of the original $k e$ of kenu) is sometimes used for either or both of these provinces. A rail line that links the two mo provinces is called Ryomo (ryo means "both"), and another line called Jomo serves the "upper mo" area.

The variety found in province names can also be seen in prefecture names. Tokyo means "eastern capital" (both kanji use the on-yomi), and the part meaning "capital" has a second possible on-yomi (kei rather than kyo). This kei is the first component of the names of many rail lines radiating from the city of Tokyo. An on-yomi syllable from the destination usually is the second syllable of the rail line name. The Keihin line connects Tokyo city with Yokohama city (hin is the on-yomi for the hama ["beach"] of Yokohama). The Keio line connects
Tokyo city with Hachioji city to the west (using its o), the Keiyo line connects Tokyo city to Chiba prefecture/city to the east (using the yo from $b a$ ), and the Keisei line connects Tokyo city to Narita city to the northeast (using the sei from nari). Many other such examples can be seen in Table 2.

The Japanese language thus provides a flexible method of forming abbreviated compounds that retain meaning and are easy to pronounce - both useful features for naming railroad companies, lines, and stations.

\section{Data Sources, Name Categories, and Mapping/Charting}

The province, prefecture, and rail name data for this analysis are part of a multifaceted "GIS spatial history of Tokyo" developed as my dissertation (Siebert 1997). In it, I mapped and interpreted Tokyo's spatial patterns and changes: (1) shoreline and river changes, (2) administrative unit changes (including provinces to prefectures), (3) population changes, and (4) development of the Kanto region's rail network. Province-to-prefecture transitions are documented from 1868 onward, and rail network developments from 1872 through 1995.

For province-to-prefecture changes, I used textual, tabular, and graphic data from a variety of historical sources, including: (1) historical atlases (Masai 1986; Kodama 1989; Ikegami et al. 1993), (2) chronologies of administrative events (Ishizuka and Ishida 1988; TMG Planning Bureau 1989; Ota 1995), (3) place name dictionaries (Papinot 1910; Yoshida 1937-1940; Takeuchi et al. 1978; Shogakukan 1996), and (4) historical censuses (Bureau of Statistics, various years from 1903 to 1995). I mapped rail lines and stations as well as province and prefecture boundaries from a series of historical topographic maps (Kokudo Chiri-in 1900s1990 s) that I scanned into the computer and digitized.

The rail component of the database includes company history, line history, and station history data. I obtained this information from five main types of sources: (1) a chronology of rail company- and line-related events during the first 100 years of railroads in Japan (Tetsudo- 
Table 1. Rail companies/lines named after provinces (1872-1995)

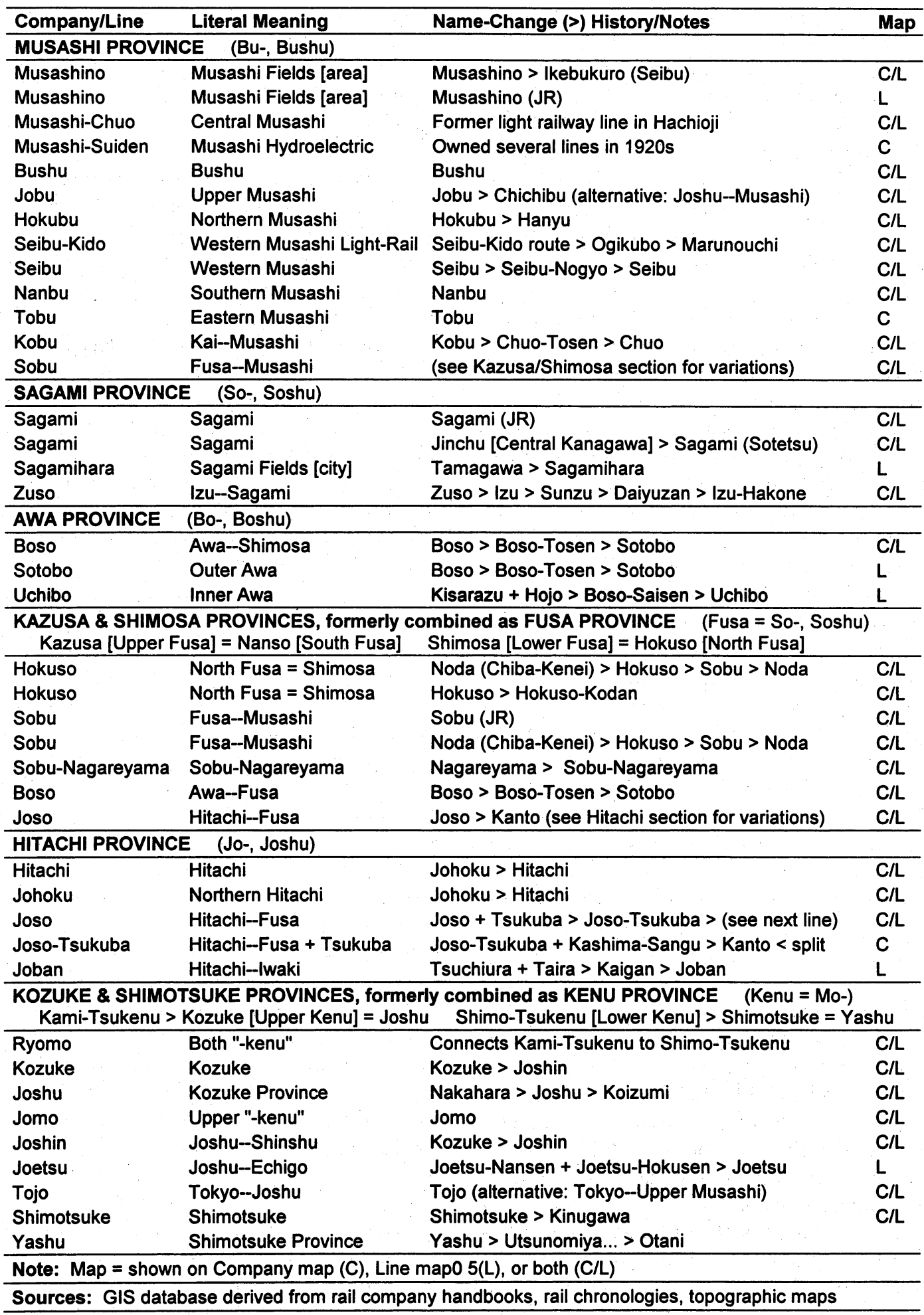


Table 2. Rail companies/lines named after prefectures/capitals (1872-1995)

\begin{tabular}{|c|c|c|c|}
\hline Company/Line & Literal Meaning & Name-Change (>) History/Notes & Map \\
\hline \multicolumn{4}{|c|}{ TOKYO PREFECTURE/CAPITAL CITY (To-, Kei-, -kyo) } \\
\hline Tokyo-Basha & Tokyo Horsecar & $>$ Tokyo streetcar lines & $(C / L)$ \\
\hline Tokyo-Keiben-Chika & Tokyo Light-Rail Subway & Precursor to Tokyo-Chika & (C) \\
\hline Tokyo-Chika & Tokyo Subway & Tokyo-Chika + Tokyo-Kosoku > Ginza & $\mathrm{ClL}$ \\
\hline Tokyo-Kosoku & Tokyo Rapid Transit & Tokyo-Chika + Tokyo-Kosoku > Ginza & $\mathrm{C} / \mathrm{L}$ \\
\hline Tokyo-Dento & Tokyo Electric Light & Owned some lines in 1920 s & C \\
\hline Tokyo-Yamanote-Kyuko & Tokyo Yamanote Express & Precursor to Teito > Inokashira & C \\
\hline Tokyo-Kogai & Tokyo Suburban & Precursor to Teito > Inokashira & C \\
\hline Tokyo-Yokohama & Tokyo--Yokohama & Became Tokyu & C \\
\hline Tokyo-Kyuko [Tokyu] & Tokyo Express & & C \\
\hline Toyoko & Tokyo--Yokohama & & L \\
\hline Tokyo-Monorail & Tokyo Monorail & & $\mathrm{C} / \mathrm{L}$ \\
\hline Tokyo-Shigai-Koka & Tokyo Urban Elevated & Built Sobu extension into Tokyo & C \\
\hline Tokyo-to (Toei) & Tokyo Prefectural & Several subway lines & C \\
\hline Tojo & Tokyo-Joshu & Alternative: Tokyo--Upper Musashi & C/L \\
\hline Keio & Tokyo--Hachioji & & C/L \\
\hline Keihin [Keikyu] & Tokyo--Yokohama Express & & C/L \\
\hline Keihin-Tohoku & Tokyo--Yokohama / NE & & L \\
\hline Keisei & Tokyo-Narita & & C/L \\
\hline Shin-Keisei & New Tokyo - Narita & & C/L \\
\hline Keiyo & Tokyo--Chiba & & L \\
\hline Keiyo-Rinkai & Tokyo--Chiba Coastal & Freight only & $\mathrm{C} / \mathrm{L}$ \\
\hline \multicolumn{4}{|c|}{ KANAGAWA PREFECTURE (Jin-) } \\
\hline Jinchu & Central Kanagawa & Became Sagami (Sotetsu) & $\mathrm{C} / \mathrm{L}$ \\
\hline Kanagawa-Rinkai & Kanagawa Coastal & Frieght only & $\mathrm{C} / \mathrm{L}$ \\
\hline SAITAMA PREFECTURE & (Sai-) & & \\
\hline Saitama Shintoshi Kotsu & Saitama New-Urban Shuttle & & C/L \\
\hline Saikyo & Saitama--Tokyo & Saikyo & $\mathrm{L}$ \\
\hline \multicolumn{4}{|c|}{ CHIBA PREFECTURE/CAPITAL CITY (-yo) } \\
\hline Chiba-Kenei & Chiba Prefecture-Operated & Various lines & C \\
\hline Chiba & Chiba & Keisei branch line to Chiba & $\mathbf{L}$ \\
\hline Chiba-Kyuko & Chiba Express & & C/L \\
\hline Chiba-Toshi-Monorail & Chiba Urban Monorail & & C/L \\
\hline Keiyo & Tokyo--Chiba & & $\mathbf{L}$ \\
\hline Keiyo-Rinkai & Tokyo--Chiba Coastal & Freight only & $\mathrm{C} / \mathrm{L}$ \\
\hline \multicolumn{4}{|l|}{ IBARAKI PREFECTURE } \\
\hline $\begin{array}{l}\text { Ibaraki } \\
\text { Ibaraki-Kotsu }\end{array}$ & $\begin{array}{l}\text { Ibaraki } \\
\text { Ibaraki Transportation }\end{array}$ & $\begin{array}{l}\text { Merged into Ibaraki-Kotsu } \\
\text { Several lines; now only one }\end{array}$ & $\begin{array}{l}\mathrm{C} / \mathrm{L} \\
\mathrm{C}\end{array}$ \\
\hline \multicolumn{4}{|l|}{ TOCHIGI PREFECTURE } \\
\hline \multicolumn{4}{|c|}{ (no rail companies or lines named after it) } \\
\hline \multicolumn{4}{|l|}{ GUNMA PREFECTURE } \\
\hline Gunma-Basha & Gunma Horsecar & & $\mathrm{C} / \mathrm{L}$ \\
\hline
\end{tabular}

Notes:

Italicized name $=$ Merged/renamed before line operation began (therefore, not included in charts and maps)

Map = shown on Company map (C), Line map (L), or both (C/L)

Sources: GIS database derived from rail company handbooks, rail chronologies, and topographic maps 
100 1972), (2) guides to station names, station histories, and name meanings (JRR et al. 1991; JTB 1985; Ikeda and Muraishi 1978), (3) handbooks published by rail companies and transit agencies (listed by company and agency name in the References), (4) many Hoikusha guidebooks to individual rail companies (listed by author), and (5) histories of Saitama railways (Oikawa 1989; Saitama 1999).

In the GIS, each rail line segment and each rail station point is linked to a database record that documents its opening date, the company name at the time it was opened, the name of the line or station at that time, and subsequent name changes and dates. The GIS spatial history also has an "events" table that chronologically lists and categorizes rail-related events. Other database tables record company information and line information. Further details of the GIS database structure are described in the dissertation.

The rail maps (Figures 2 to 7 ) of company, line, and station names were produced by querying the name history fields of the line and station data tables linked to geographic files. Each map is a cumulative view of all occurrences of a particular name category in the years from 1872 to 1995 . If a particular rail line segment (i.e., a station-to-station link) or station met the query criteria at any time in that segment's or station's history, it is included in the mapped category.

The GIS database can be used to produce maps showing conditions for given time points or time periods, to reflect the temporal sequencing that is obvious from the timeline charts (Figure 8, discussed later). Similarly, separate maps showing company, line, and station names or province or prefecture linkages can be produced. Labeling and differentiating each company, line, and station was not possible on the maps included here due to the great number of features and the limitations of black-andwhite printing in a small-format journal.

Because each map is a cumulative temporal view, be careful not to think only in terms of the current names of companies, lines, and stations. For example, the current Chichibu line is not named after a province, but it was called Jobu (named after Musashi province) when its first segments were built from Kumagaya to Chichibu. Only those segments that operated under the Jobu name are shown as provincebased, not the extensions that were built after the company and line name were changed to Chichibu.

The same line segment may appear in more than one company map or line map because its ownership or name changed from one category to another. For example, the Jinchu company (with a prefecture-based name) was bought by the Sagami company (with a province-based name), and thus appears in both Figures 2 and 3 as a company, as well as Figures 4 and 5 as line.

Rail lines have not been mapped all the way to the edge of the map areas shown in Figures 2 to 7 . The GIS spatial database currently only includes lines that are completely within the Kanto region or that are affiliated with it (e.g., some of the Izu and Suruga lines that at one time were part of a company that included a name based on Sagami province). Also, some long-distance trunk lines (Tokaido, Tohoku, Joetsu, and their super-express new lines) are not mapped up to the edge. No streetcar lines are mapped; recording their history is a future time-consuming task of developing the GIS database.

Most current and historical stations have been mapped, except for stations along some abandoned light rail lines (pending location of suitable source materials, these are mapped just as lines, without stations). Some station name changes have not yet been recorded because I have not found suitable historical records. There thus may be more historical instances of province-, prefecture-, and capital-based station names than those mapped in Figures 6 and 7; however, the number of unrecorded stations is small.

The rail name history charts (Figure 8) were produced from a timeline spreadsheet that records and keeps running totals of company and line names and changes, with one record per year from 1870 to 1995 . Each record has one field recording additions, renamings, mergers, and dissolutions of rail companies and another field recording openings, renamings, mergers, and closures of lines.

The timeline spreadsheet also has two sets of 
fields tallying the number of railroad companies and lines in seven categories of name origins: (1) country (e.g., Japanese National Railways), (2) region (e.g., Kanto, Tohoku, Tokaido), (3) province, (4) prefecture, (5) capital = prefecture (see next section), (6) capital=other (see next section), and (7) other, including settlements (cities, towns, villages, counties, or inhabited places), natural features (rivers, mountains, etc.), and directional or abstract spatial terms (e.g., east-west line).

In Figure 8, the top two charts are for company names and the bottom two for line names. In each pair, the first chart shows all seven categories as an area chart, and the second chart shows province vs. prefecture vs. capital (with two subtypes) as a line chart. The top view in each pair shows the relative total numbers of companies or lines in each of the seven categories, as well as the overall total (the position of the uppermost curve). The categories of particular interest are shaded: dark gray for province-based names, light gray for prefecture-based names, closely spaced lines for the capital=prefecture category, and thinly spaced lines for the capital=other category.

\section{Decision Rules for Interpreting Company, Line, and Station Names}

Due to the nature of how province, prefecture, and rail names are formed and used in Japanese, it is not always easy to determine whether a company, line, or station name is based on a province name, a prefecture name, or neither, or which province or prefecture it is based on. My decision rules and examples for handling some of the complexities and other situations are summarized next.

Of Japan's 47 prefectures, 29 have the same name as the prefectural capital city. Most of these cities are former castle towns from the medieval era and gave their name to the modern prefecture established around them. The remaining 18 prefectures derive their names from, or share them with, minor villages, towns, counties, or other features.

Because prefecture names and capital names sometimes overlap, I include them both in Table 2 (but with "P" and "C" differentiating them in the "Type" column). I also show their spatial distribution on the same map (Figure 3 for companies, Figure 5 for lines, and Figure 7 for stations), with symbols differentiating three types: (1) prefecture for railroad companies/ lines named after a prefecture, (2) capital $=$ prefecture for those named after a capital city that has the same name as the prefecture, and (3) capital $=$ other for those named after prefectural capitals that have a different name than the prefecture.

Only two of the Kanto region's seven current prefectures have the same names as their current capitals. Tokyo prefecture is named after the capital city of the country, which was called Edo until it was changed to Tokyo in 1868; the prefecture of Tokyo was established in 1871 (and substantially expanded in 1893). Chiba prefecture was established in 1873 , taking its name from the small castle town of Chiba, which became the prefectural capital.

Should companies and lines named after Tokyo and Chiba be treated as prefecture-based or capital-based? After considering the likely origin and areas served, I decided to treat most as capital-based because they link two cities (Tokyo to Yokohama, Hachioji, Narita, Chiba, etc.) or mainly serve the city itself. In a few cases the distinction is more difficult. The Toei subway lines serve the city of Tokyo, but I treat them as prefecture-based due to the meaning of the word ("prefecture-operated"). Although the area served by the Keiyo-Rinkai freight line is not between Tokyo and Chiba cities (it is south of Chiba city), I base its assignment on the name (just as for the Keiyo commuter line between Tokyo and Chiba cities).

The capital=other category includes capitals of the other Kanto prefectures: Yokohama for Kanagawa prefecture, Urawa for Saitama prefecture, Mito for Ibaraki prefecture, Utsunomiya for Tochigi prefecture, and Maebashi for Gunma prefecture. Some prefectural capitals changed during the late 1800 s when the new prefectures and capitals were still being sorted out. I include a rail company, line, or station in the capital=other category only if it was in operation when the capital was at that location or if the name is identical to the prefecture.

Shimotsuke province was initially divided 


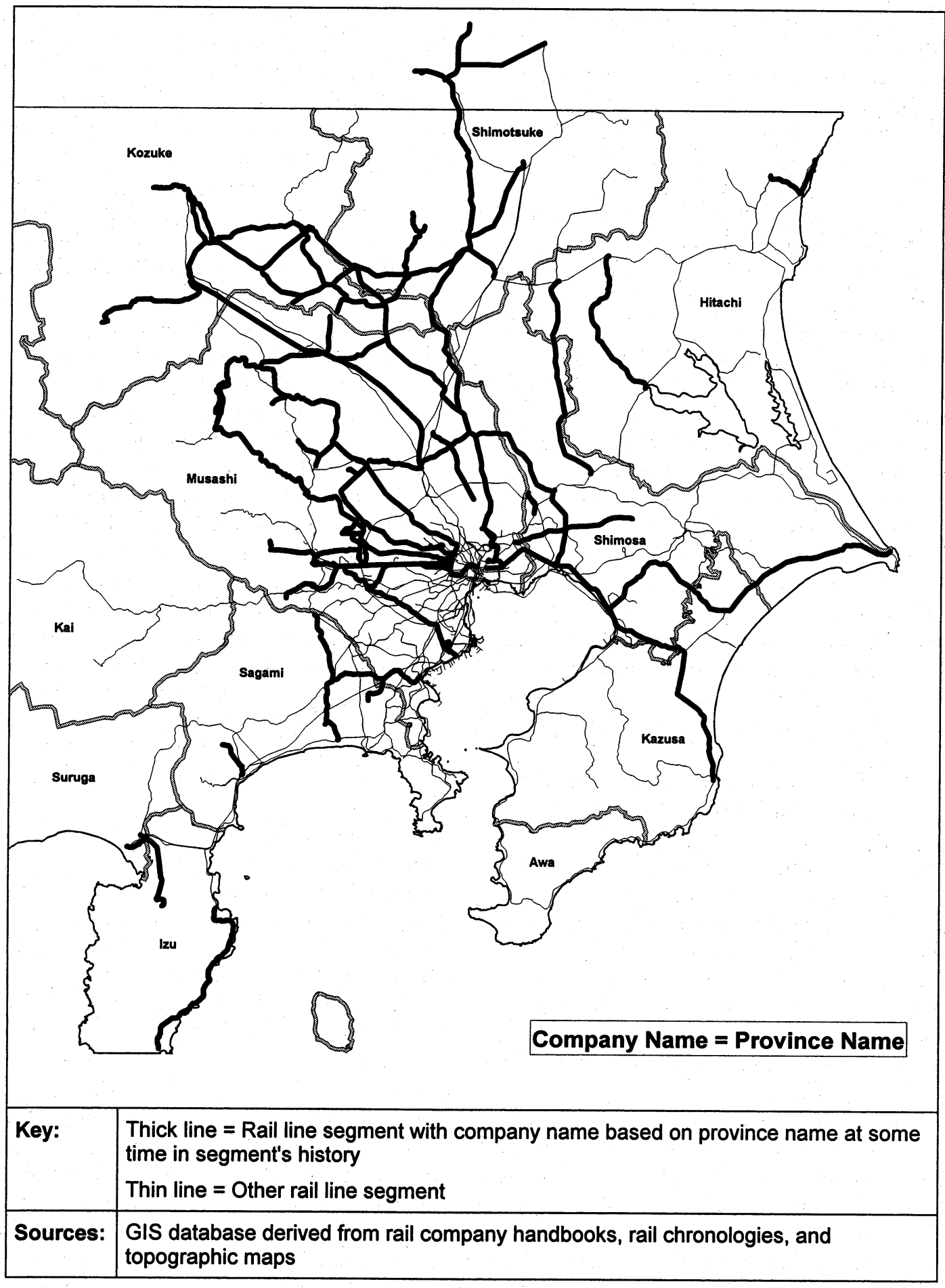

Figure 2. Rail company names and province names (Kanto 1872-1995). 


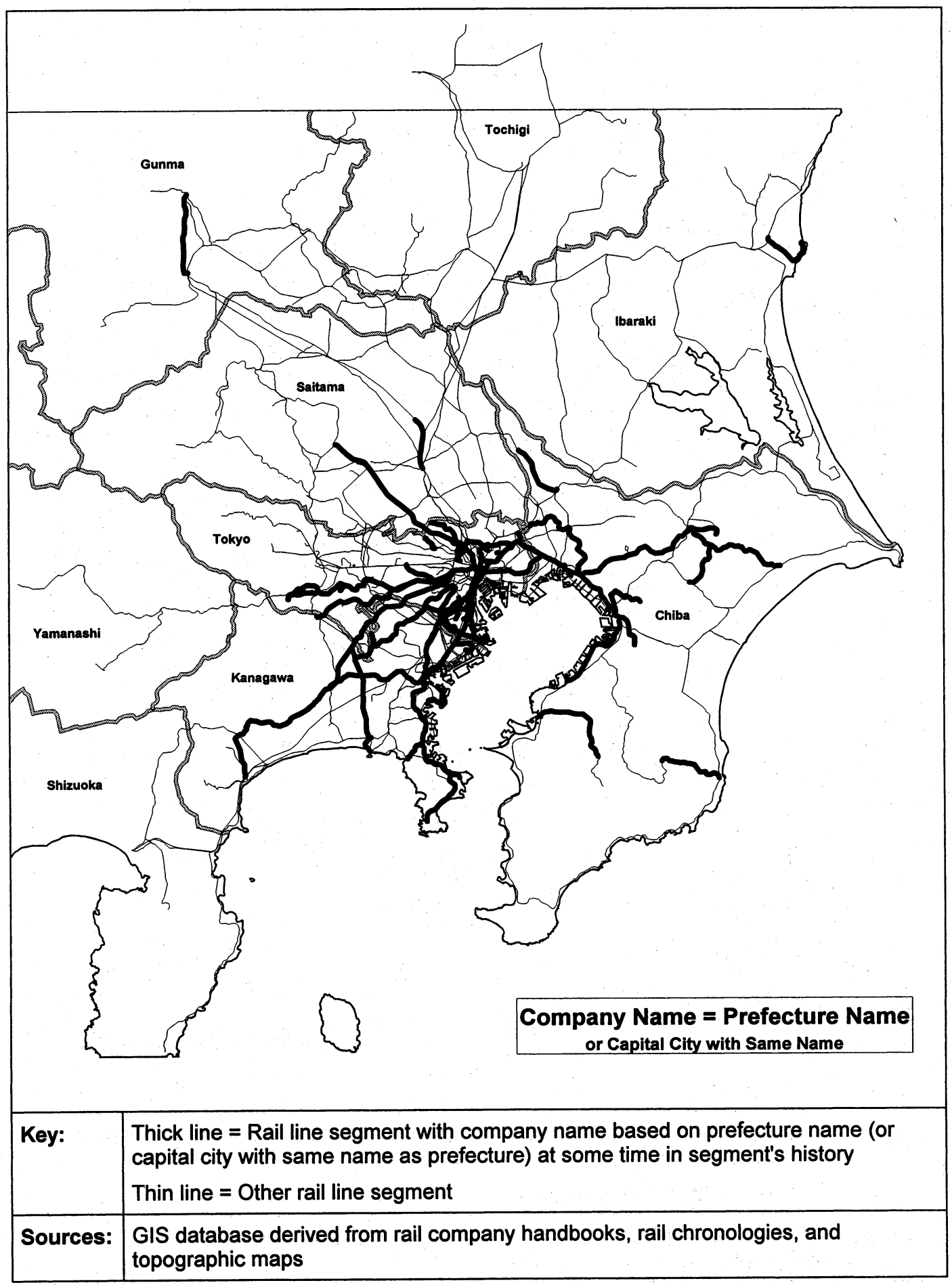

Figure 3. Rail company names and prefecture/capital names (Kanto 1872-1995). 


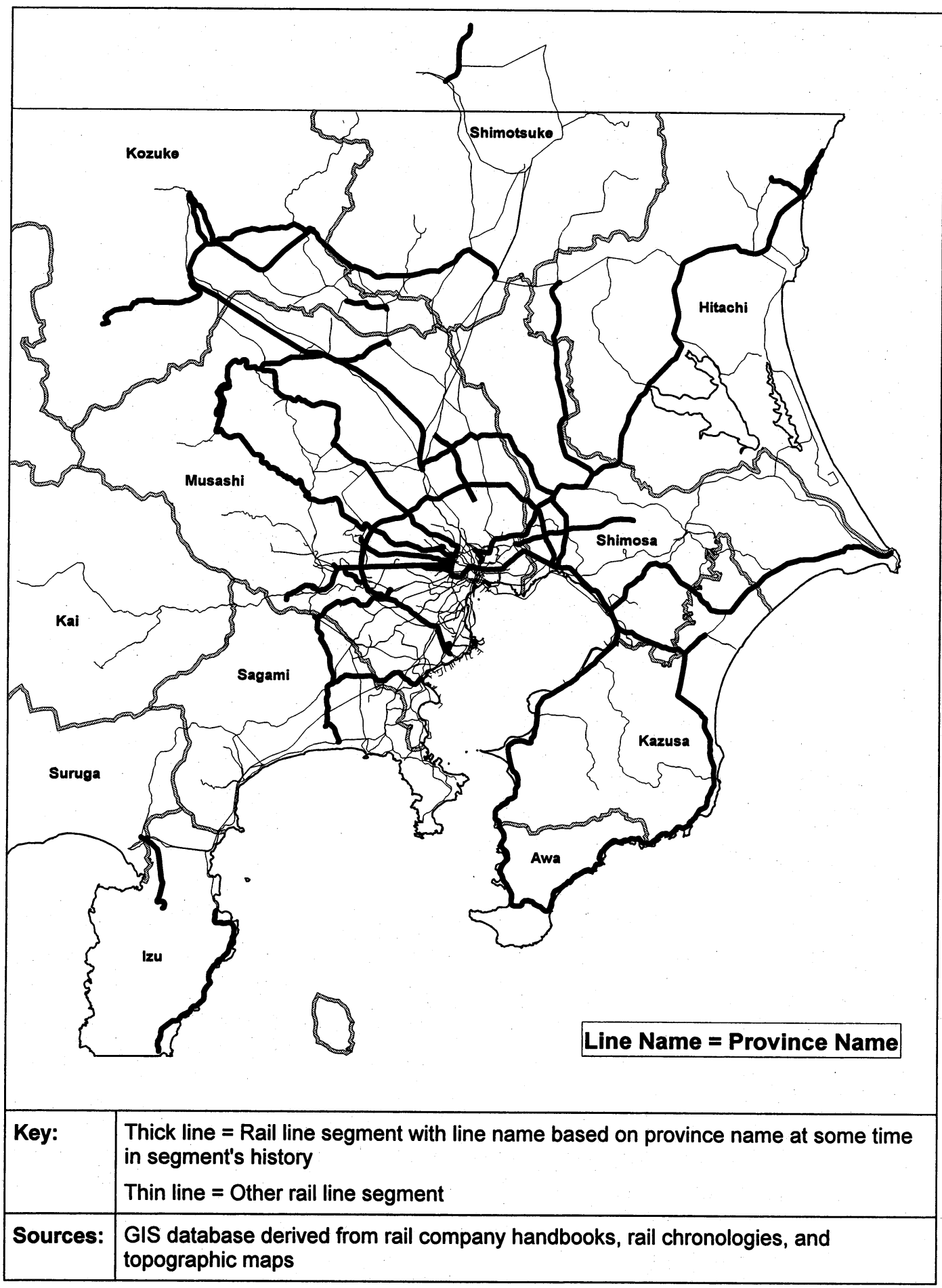

Figure 4. Rail line names and province names (Kanto 1872-1995). 


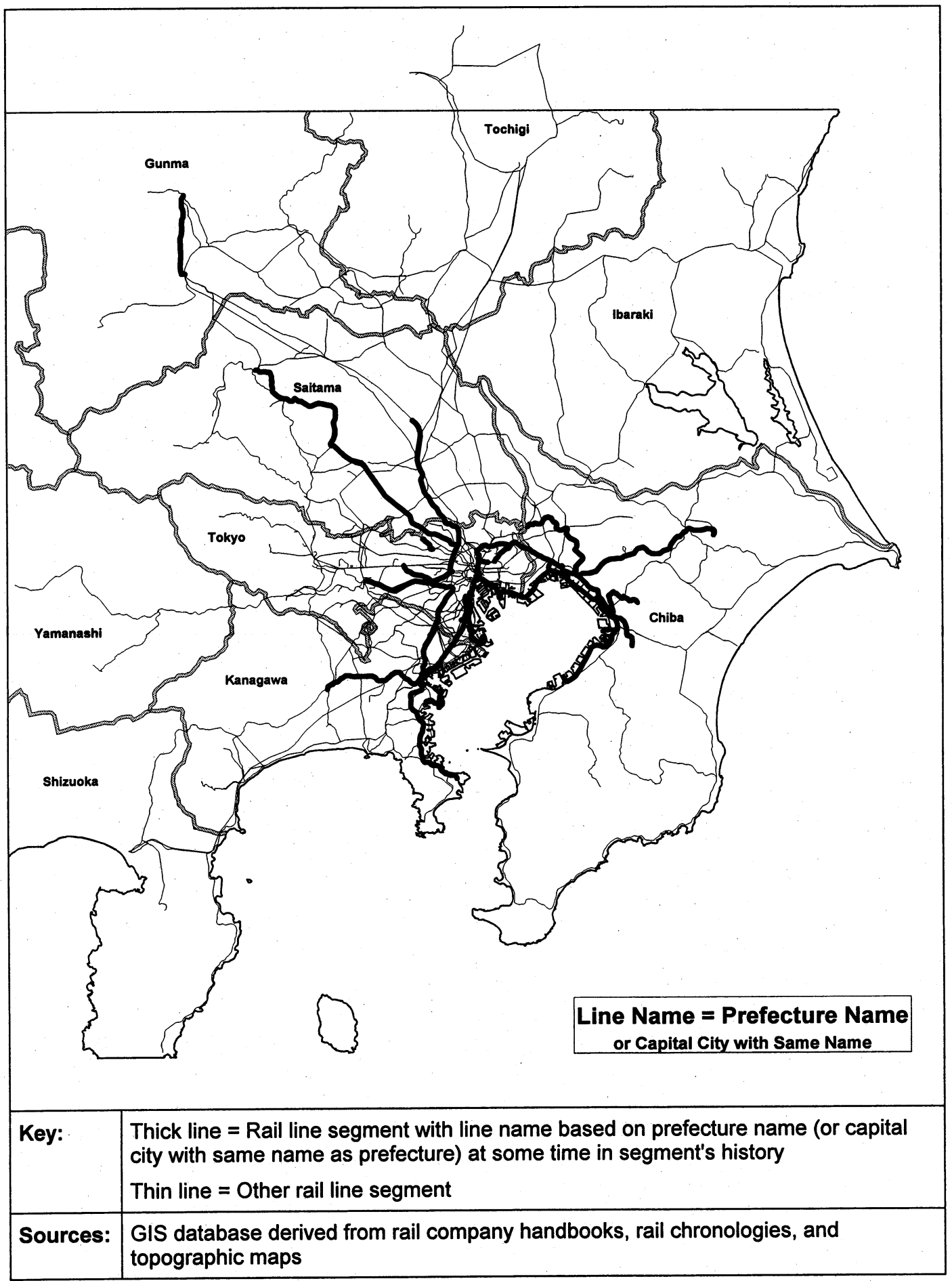

Figure 5. Rail line names and prefecture/capital names (Kanto 1872-1995). 


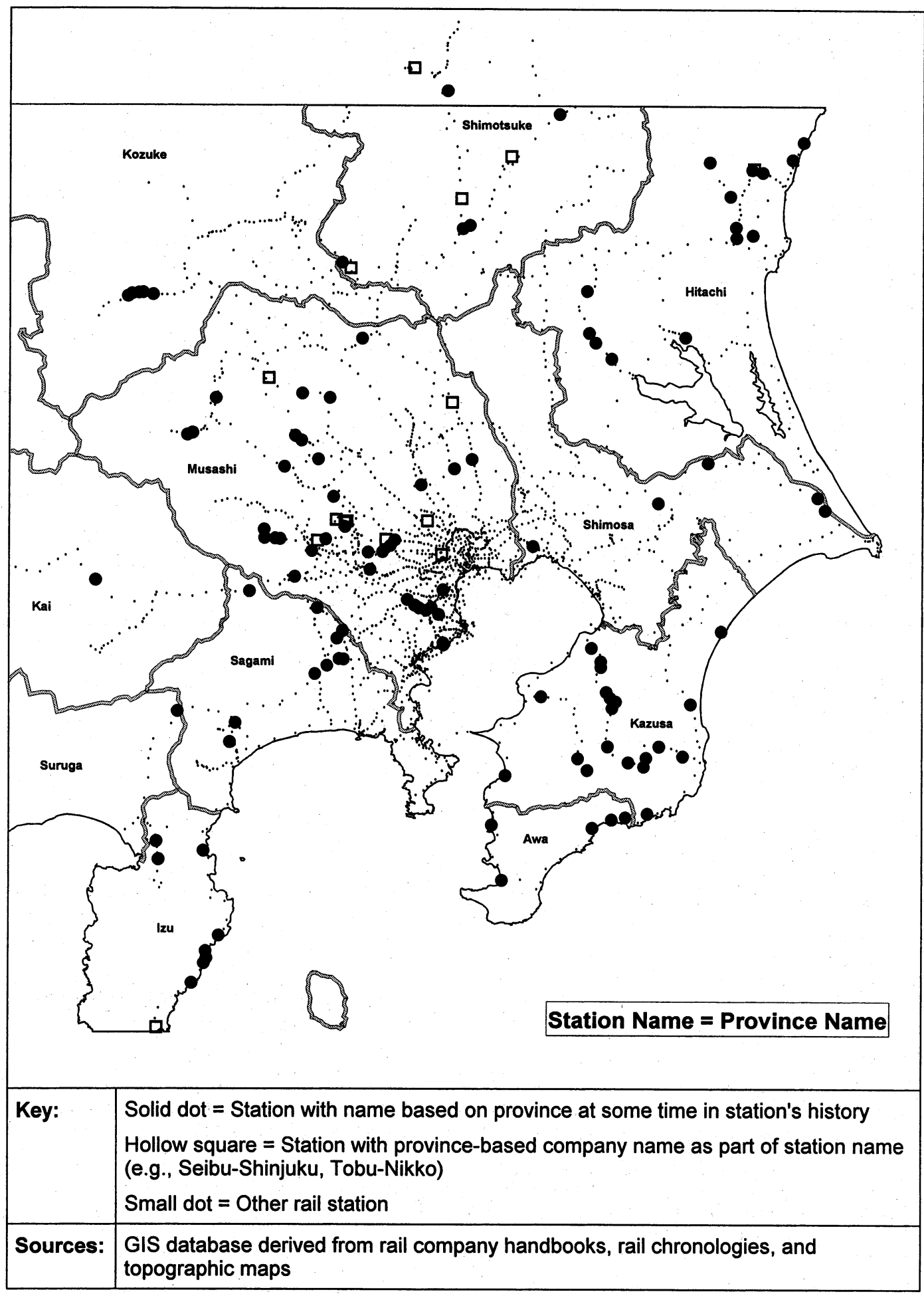

Figure 6. Rail station names and province names (Kanto 1872-1995). 


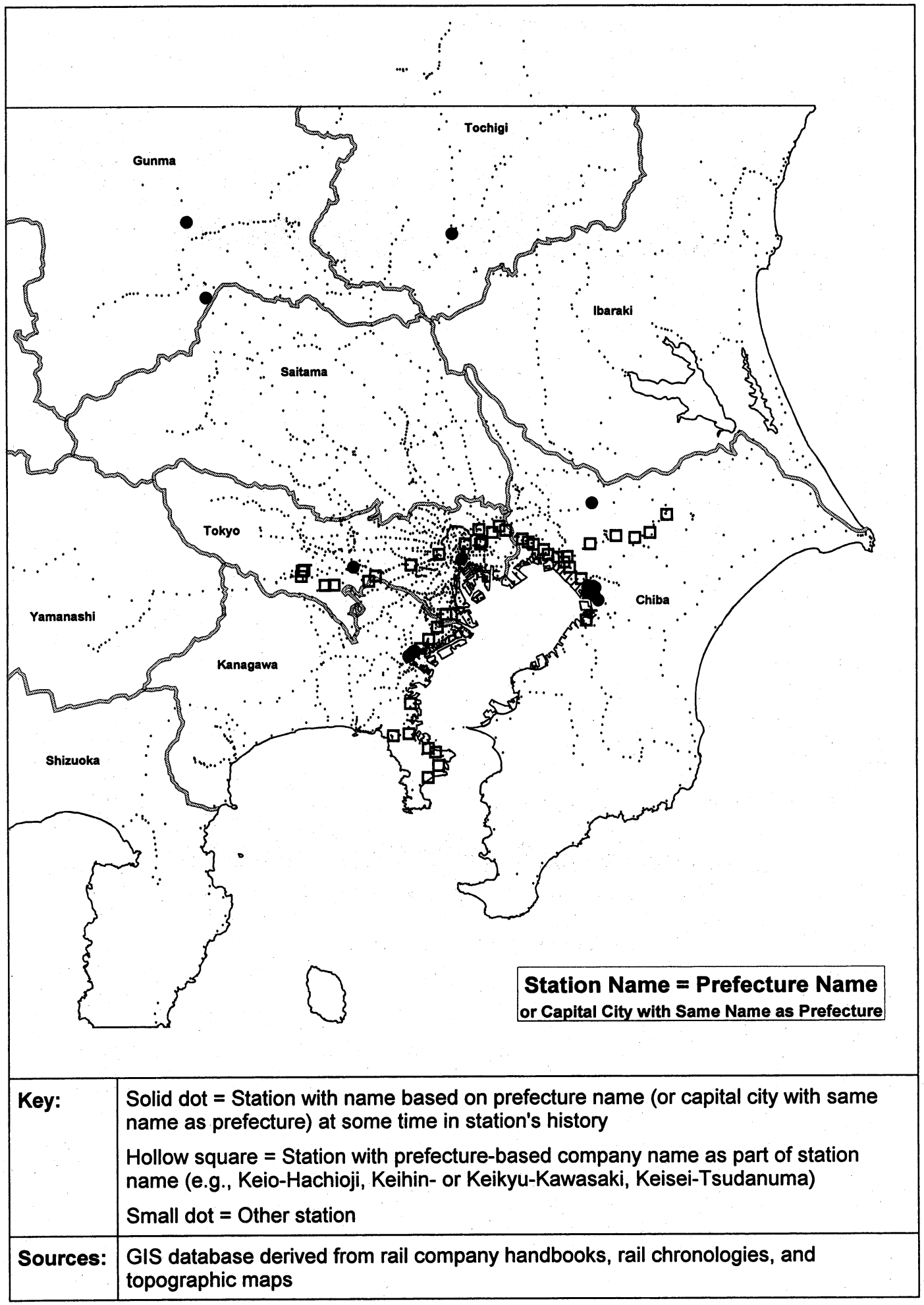

Figure 7. Rail station names and prefecture/capital names (Kanto 1872-1995). 

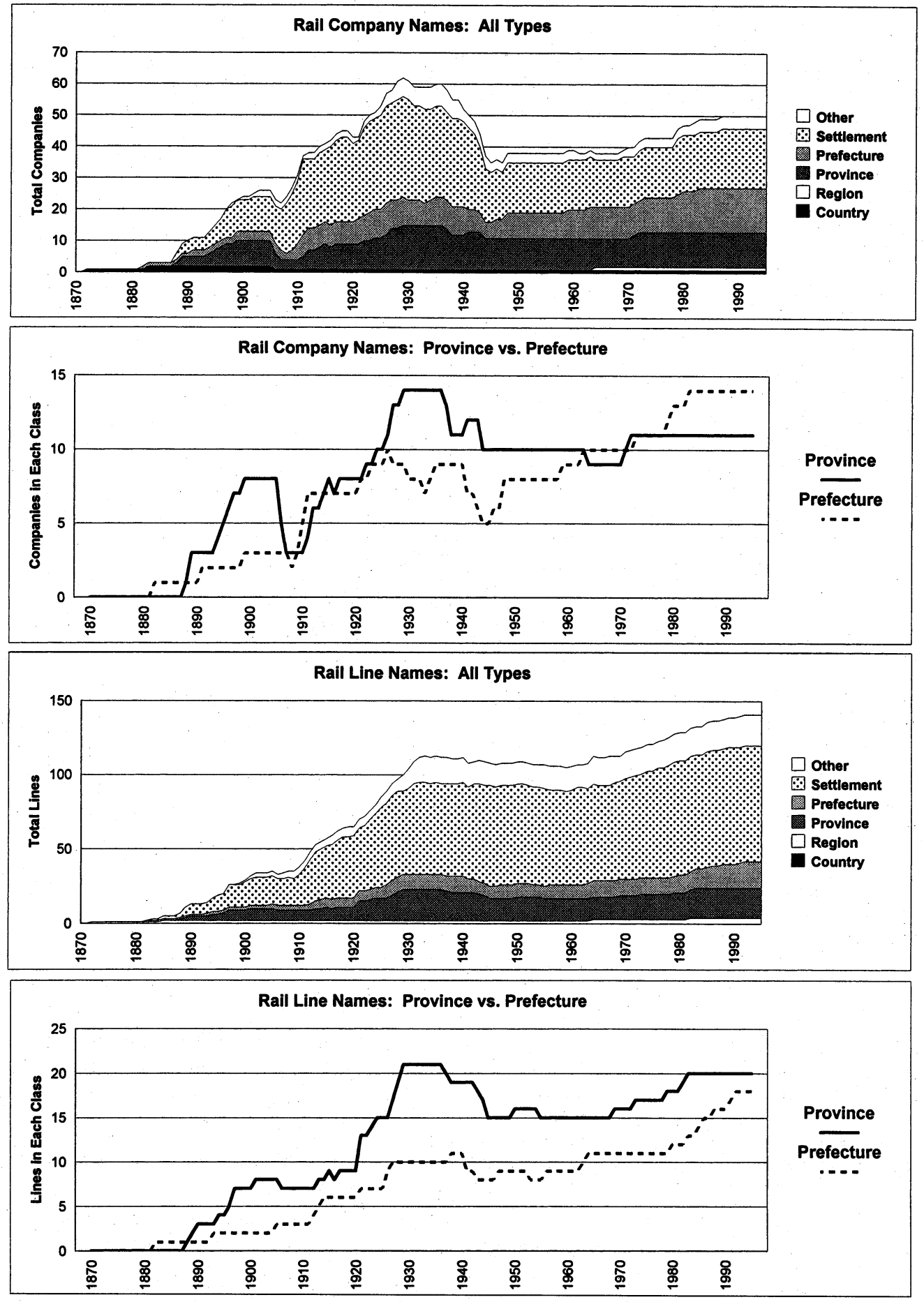

Figure 8. Timelines of types of rail company and line names (1872-1995). 
into Tochigi prefecture (which also temporarily included part of Kozuke) with Tochigi as its capital, and Utsunomiya prefecture with Utsunomiya as its capital. In 1873 Utsunomiya prefecture merged into Tochigi prefecture, and in 1884 Utsunomiya replaced Tochigi as the capital (Shogakukan 1996). Stations with Tochigi in their names opened after the capital moved to Utsunomiya, so on that basis I would not include them; however, because the prefecture and city name are identical and related, I include Tochigi. Companies, lines, and stations with Utsunomiya names all operated when Utsunomiya was the capital, so I map them. (I do not include the current "Utsunomiya" commuter service on the Tokyo-to-Utsunomiya portion of the JR Tohoku line because the line name is Tohoku.) The Kozuke-to-Gunma transition history is more complex. The relevant point is that although Takasaki was briefly Gunma's capital, the capital had already changed to Maebashi before the Takasaki lines and stations were opened. Therefore, I include Maebashi stations but not Takasaki stations or the Takasaki lines.

Some prefectures have the same name as a town that did not become the capital: Kanagawa was an important post-town along the Tokaido route, but nearby Yokohama became the capital of Kanagawa prefecture and later annexed Kanagawa town. Several station names have been based on the town of Kanagawa; I include them in the prefecture category because the written name is identical. In contrast, although Hitachi province and Hitachi city have the same pronunciation, the kanji are different. Hitachi is an old province name, whereas Hitachi city's name is relatively young. In the company and line maps, this confusion is hardly noticeable, because most of the length of the line that is now called the Hitachi line (after the city) was built when the line was still called Johoku (the alternative name for the province Hitachi). Almost all station names that use Hitachi as a prefix use the province's kanji, so I do map them.

Occasionally several new companies competed for permits to build a line connecting the same area, or a company started with one name but changed its name before its first line opened. I only use the name of the company that actually opened the line. Tokyo Yamanote Kyuko and Tokyo Kogai companies merged into the Teito company before the Teito (now Inokashira) line was opened. My tally only considers the Teito company and line. The history of competing preoperational companies - as well as authorized but never-built lines-is just too great to be covered here. Including some but not all such preoperational companies would have made the comparison inaccurate.

When I know the establishment date of the company that opened the line, I use it in the company timeline. If I only know the first line opening date, I also use that date for the company's establishment. When the "company" is a government agency or a power company, I use the date it opened its first line.

Although I map and tally rail company and line names separately, they are often related. The first line built by a rail company usually has the same name as the company, but then may change later when the company expands by building or acquiring more lines. For example, the first line opened by the Musashino company was called the Musashino line but later changed to the Ikebukuro line when Musashino acquired the Seibu company, changed the company name (to Seibu), and then changed various line names.

Sometimes the company name serves as a prefix to the line name. If the company's literature normally uses the company's name as part of the line name, I include it. Seibu-Yurakucho and Seibu-Chichibu are treated as provincebased lines because Seibu is almost always used as a prefix to distinguish these two lines from the Eidan Yurakucho line and the Chichibu company's Chichibu line. In contrast, if the corporate handbook normally uses the name by itself, I use it separately even though common practice frequently combines them. When the Musashino company became the Seibu company and changed its original line's name to Ikebukuro, I removed that line from the province-based tally even though in common practice it often is referred to as the SeibuIkebukuro line. I also use the company name as part of the line name when the line name itself has only a number (as in Toei's Line 12, and the 
two Yokohama subway lines).

When a line retains its original name (i.e., the company name), it often is referred to as the hon-sen ("main line") when other lines are built. In this case, based on common usage, I use the company's name as the line name (e.g., Keio for Keio's main line, Keikyu for Keihin-Kyuko's main line).

A rail company and line name can be based on the area originally planned to be served (as revealed in permits granted) rather than the area actually served. The Tojo line connects Tokyo to Yorii, where it connects to the line originally called Jobu (Upper Musashi). It might be thought that the jo of Tojo is based on this connection (Tokyo to Jobu). However, it actually comes from Joshu (Kozuke province), the terminus in the initial permit (Oikawa 1989; Saitama 1999). Tojo company is mapped in the capital category. It was later bought by Tobu (a province-based company), so it also appears in the province map. As a line, I map it both as capital-based and province-based because it contains both elements in the name. Another ambiguous name is Tobu. The $b u$ clearly means Musashi, but the to could mean either "east" (from Tokyo) or "eastern" (as in "Eastern Musashi"). Tobu serves eastern Musashi, just as Seibu serves western Musashi, Nanbu southern Musashi, and Hokubu northern Musashi. I therefore treat Tobu as province-based even though some people may consider it to mean Tokyo city to Musashi province. Tokyo is in Musashi, so saying Tokyo to Musashi does not make geographic sense.

Other companies or lines have had a province- and prefecture-based name history (but not combined at the same time in the same name, as Tojo). Chiba prefecture operated a line to Noda town, later privatized it to Hokuso, which later became Sobu (the second Sobu) before being bought by Tobu. Portions of it show up on both types of maps: as Hokuso, Sobu, and Tobu on the province map, and as Chiba on the prefecture map. In Kanagawa, the prefecture-based Jinchu ("Central Kanagawa") company and line later became the provincebased Sagami (Sotetsu) company's main line. The Sagami company's original Sagami line became the JR Sagami line.
Some rail names are based on a subarea within a province that uses the province name as part of its name. The two Musashino lines are named after the upland area called Musashino (Musashi "fields"). The Sagamihara line is named after its destination city, which is named after a similar physiographic district of Sagami province. This area sometimes is also called Sagamino (with a station by that name), using the same kanji as in Musashino (Shogakukan 1996). Although these two names are only indirectly connected to provinces, I treat them as province-based. Similarly, Fusamoto and Higashi-Fusamoto stations in the former province of Fusa derive their name from the village and town of Fusamoto, which means the "center" or "origin" of Fusa. Although it can be argued that Fusamoto should not be treated as province-based, for consistency with Musashino and Sagamihara, I map it as province-based. All three names include the province name itself and represent a district within the province. In contrast, although the Chugen company's name is derived from the Kanto Plain ("center of the plain"), it uses the generic part of the name rather than the unique, proper-noun part, so I do not treat it as being region-based.

Finally, many station names have the company name as a prefix (e.g., Keisei-Ueno, SeibuTachikawa). These names are indirectly derived from province or prefecture names, so I map them separately (as hollow squares rather than solid dots). The only confusing situation is the station called Johoku-Ota in Hitachi province. Should it be mapped as the province-based name Johoku (north Hitachi) or as the name of the company that opened it (Johoku)? I chose the latter. Because no numerical tallies have yet been done for station names, this decision to treat company-based station names separately only affects the visual display in Figures 6 and 7.

\section{Spatial and Temporal Patterns of Rail Company and Line Names}

In the Kanto region between 1872 and 1995, there have been over 175 rail company names, over 275 line names, and over 2,000 stations 
(many with one or more name changes and some with as many as five different names). This section looks at the spatial and temporal patterns of their names in relation to provinces, prefectures, and capitals. General patterns are discussed here; specifics (including relevant company and lines names) are described for individual provinces and prefectures in a later section.

\section{Spatial Patterns of Company Names}

Looking spatially at province-based rail company names (Figure 2 and also Table 1) and prefecture/capital-based rail company names (Figure 3 and also Table 2), we can observe that companies with province-based names are spread throughout the Kanto region, whereas those with prefecture- and capital-based names are concentrated in and around Tokyo itself, with only a few outside that area.

There is some Tokyo-to-northwest dominance of province-based company names (Figure 2), with many Musashi-containing companies radiating outward from Tokyo or filling in other parts of the former province. Several companies have Kozuke- and Shimotsukebased names; those former provinces are also served by many lines of the Musashi-based Tobu company. Hitachi, Shimosa, Kazusa, and Sagami provinces have several companies. Awa has one (Boso), but it did not extend all the way to Awa before it was nationalized.

In the prefecture/capital-based company name map (Figure 3), the overall pattern is concentration in and near Tokyo, with southward and southwestward dominance. Capital-based names are more prevalent than prefecturebased names, but remember that many of these are overlapping capital=prefecture names based on Tokyo or Chiba.

There are very few prefecture-based company names (thicker solid lines). Except for the Tokyo prefecture-operated subway, most are found outside of Tokyo itself, but with only two for Kanagawa, one for Saitama, one for Chiba (but five lines), two for Ibaraki, none for Tochigi, and one for Gunma.

Most capital $=$ prefecture names (broken lines) are for companies that serve Tokyo, Kanagawa, and Chiba prefectures, with only one in Saitama (the Tojo company). Note that the Odakyu company serving areas in Kanagawa from Tokyo appears in this map because the company was temporarily part of the Tokyu company during the war; the same is true for the Keio and Keihin-Kyuko companies, but their own names are also capital-based.

In the capital=other category (thinner solid lines), there are two companies with Yokohama-based names, three with Mito, two with Utsunomiya, and one with Maebashi. (One of the Mito lines also appears in the province map because it changed its name to Joyo one year before it went out of business.)

\section{Spatial Patterns of Line Names}

Looking spatially at province-based rail line names (Figure 4 and also Table 1 ) and prefecture/capital-based rail line names (Figure 5 and also Table 2), we can observe the same overall patterns as for companies. There are many more lines with province-based names than prefecture- or capital-based names. Province-based companies are spread throughout Kanto, whereas those with prefecture-based and capital-based names are concentrated near Tokyo.

For province-based line names (Figure 4), the lines are spread out more than they are for companies (Figure 2), without a clear northwestward dominance. In this map, only lines with province-based names appear, not whole company systems. Thus, there is a thinning out of lines in the vast areas of Musashi (stretching north and west from Tokyo) served by Seibu and Tobu, because only some of their lines have province-based names. Elsewhere, some lines now appear whose companies did not have province names, such as the JNR/JR Musashino line, the Joban line through Hitachi province, and the western Boso line (now Uchibo) through Shimosa, Kazusa, and Awa provinces. The eastern Boso line (now Sotobo) is mapped all the way to Awa; the company map only includes the portion of the line that was built before the Boso company was nationalized. A line in southwest Sagami province that has a province-based company name but unrelated line name (Daiyuzan) does not appear.

For prefecture/capital-based line names 
(Figure 5), the lines are concentrated even more in the immediate vicinity of Tokyo than they are for company names (Figure 3). However, the number of lines is lower (both for capitalbased and prefecture-based), for the same reason as stated above for provinces. The five lines operated by Chiba prefecture are not mapped, because their line names were different. There are only a few additions, such as the Saikyo line between Saitama and Tokyo, the Keiyo line between Tokyo and Chiba, Tobu's capital-based Utsunomiya line in Tochigi, and an extended capital-based Tojo line after it was acquired by Tobu.

In summary, when we spatially compare province versus prefecture as well as company versus line, we can conclude that the greatest difference in quantity and distribution occurs for province-based lines (widely, uniformly dispersed) versus prefecture-based lines (few, and highly concentrated). An explanation for this will become apparent when we look at the temporal patterns.

\section{Timelines}

Looking at the rail company name timelines (top two charts in Figure 8), several patterns can be observed. First, the total number of companies in existence at a given time (i.e., the topmost curve) reached an initial small peak in the early 1900s (several private companies were nationalized in 1906 and 1907). Second, it reached its largest peak in the $1930 \mathrm{~s}$, after many new suburban commuter companies were established (primarily around Tokyo) and then gradually merged together. Third, a significant drop occurred in the late 1930s and early 1940 s due to dissolutions and mergers during World War II. Fourth, there was slow, steady expansion in the 1950s and 1960s, then more rapid growth in the 1970s and 1980s, followed by stabilization in the early 1990s.

For company name types, the "other" category has been the largest throughout, followed by province-based names, then capital=prefecture names (which, as seen in the second chart, finally overtook province-based names around 1960). Prefecture-based names and capital= other names have been relatively scarce throughout the entire period. If we consider prefecture and capital=prefecture together, they would be almost up to the province-based curve for most of the period after about 1910 , except the 1930s province peak. The gaps between province-based and prefecture/capital = prefecture were temporarily closed when some province-based companies were nationalized and some suburban companies with prefecture/capital names were established.

The bottom two charts in Figure 8 show similar timelines for rail line names. The most striking difference between the total number of companies versus total number of lines (the uppermost curves of the "All Types" charts) is that lines did not drop precipitously in 1906/ 1907 or in the war years (late 1930s to early 1940s). When companies were nationalized, acquired by other private companies, or temporarily combined during the war, the number of companies declined, but usually the lines remained in operation under the same name. There were, however, a significant number of closures of province-based lines in the war years (the sharp drop in the bottom chart), but these were made up for by line openings in other categories, so the overall curve only slightly declined.

The overall pattern for line growth is rapid growth from the 1880s through about 1930 , very gentle decline through the 1950 s, then steady but less rapid growth from the 1960s onwards. This reflects rapid introduction of lines during the early years, a few abandonments in mid-century, then steady growth, primarily of new subway lines but also some new suburban lines and "new transit system" lines, including monorails and automated guideway lines.

Looking at line name types, the "other" category dominates throughout all time periods, with province-based names much further behind, followed even further behind by capital $=$ prefecture, capital $=$ other, then prefecture. Comparing province, prefecture, and capital (bottom chart), the separation is much more consistent and larger than for company names. For these, province-based line names have always been greater than the other related types (except for the 1880s); this is true even if prefecture and capital $=$ prefecture would be 
combined.

In summary, when we consider the history of province-, prefecture-, and capital-based rail company and line names in the Kanto region, we can conclude that province-based names have been more common than prefecture- or capital-based names for most time periods. Thus, the overall temporal pattern is the same as the spatial pattern described in the previous section.

\section{Spatial Patterns of Rail Station Names}

The next issue to evaluate is the influence of province and prefectures on rail station names. In this case, the underlying GIS database contains fields that record the changes of names for most of the Kanto region's more than 2,000 historical rail stations. Station name histories for some outlying lines have not been obtained yet due to lack of response from some existing companies, or my inability to locate historical records of station positions and name changes for some abandoned lines. Therefore, the maps are not complete, and a numerical tally has not yet been produced. Considering where these lines are and what their line names are, my assumption is that more of the missing historical names would be province-based rather than prefecture-based.

One complicating factor is that many stations have the company name as part of the station name (e.g., Seibu-Shinjuku, Keikyu-Kawasaki, Keisei-Narita, Keio-Tama-Center). Because these reflect company ownership rather than province or prefecture origin, I map them with a different symbol (hollow square) rather than including them with direct province- or prefecture/capital-based station names (solid symbols). Furthermore, such company-based names complicate the display of province or prefecture relationships because a rail company with a name based on one prefecture often gave its company name to stations along extensions of its lines into other prefectures (e.g., Keisei lines extending into Chiba).

Province-based and prefecture/capital-based station names are mapped in Figures 6 and 7. As was the case for company and line names, there are many more province-based names than prefecture-based names, and the provincebased names are spread throughout the Kanto region. Keep in mind that these maps show historical and current names, so some stations appear that currently do not have province-, prefecture-, or capital-based names.

Almost all of the province-based station names (solid dots in Figure 6) are compounds beginning with the name of the former province they are located in, using either the Japanese form (kun-yomi) or Sino-Japanese form (onyomi). For some Kanto provinces, both forms are used, such as Musashi-Itsukaichi and Bushu-Karasawa in Musashi province, and Shimotsuke-Hanaoka and Yashu-Hirakawa in Shimotsuke province. There is a geographic pattern to this dual usage: All Bushu names are in northern Musashi (but there are also Musashi names in the north), and most Yashu names are in southern Shimotsuke. In most other Kanto provinces, only the kun-yomi form is used for station compounds, such as Sagami-Kaneko, Awa-Kamogawa, Kazusa-Ichinomiya, ShimosaManzaki, and Hitachi-Aoyagi. (None of the Hitachi compounds is based on the city of Hitachi; one station name is based on the Hitachi industrial company, and hence is not mapped.) Stations in Kozuke province use the on-yomi form (e.g., Joshu-Nanokaichi). Musashi, Sagami, and Kazusa provinces also have a few province-based station names that are indirectly derived from the province name, such as Musashinodai, Sagamihara, and Fusamoto (see earlier discussion of why they are included).

Musashi province has the most provincebased station names (37), followed by Kazusa (19), Hitachi (12), and Sagami (10), then Awa, Shimosa, Shimotsuke, and Kozuke each with five. These numbers may increase when information on some of the abandoned light rail lines is obtained. Very few stations have compound names that include a province-based railroad name (hollow squares in Figure 6); those that appear are for Seibu and Tobu.

There are comparatively few prefecturebased and capital-based station names (Figure 7). Naturally, the capital-based categories have clusters at the center of each capital: In the capital = prefecture category, there is Tokyo station itself and one other (the indirectly 
derived Todaimae), and there are several in Chiba city (and one in Chiba New Town). In the capital = other category, there are several each in Yokohama in Kanagawa prefecture, Urawa in Saitama prefecture, Mito in Ibaraki prefecture, Utsunomiya in Tochigi prefecture, and Maebashi in Gunma prefecture.

Surprisingly, there are almost no genuine prefecture-based station names: only two in Gunma and one in Tokyo (a suburban racetrack station with Tokyo in its name). The solid dots in Tochigi are for Tochigi city and those in Kanagawa for Kanagawa town. As explained earlier, I have mapped them based on their identical meaning, even though they are not strictly prefecture-based. It is only when we add stations that include prefecture-based company names (hollow squares) that we find a larger number of stations. These represent stations on the Keikyu, Keisei, and Keio lines radiating out from Tokyo.

These station maps show the clear dominance of provinces over prefectures and capitals as origins of rail station names in the Kanto region. Because I have not yet produced a timeline spreadsheet for station names, I cannot make charts similar to Figure 8. However, based on my preliminary investigation of the underlying database records in which I have recorded name changes, I would say that there probably has been a slight peak, with some names getting converted to forms without the province name, and other province-based names disappearing when rail lines were abandoned. However, the overall pattern remains one of province dominance.

\section{Summary of Patterns by Province and Prefecture}

Looked at by province or prefecture, the following general patterns can be seen from the rail company, line, and station name histories and distributions.

\section{Musashi Province}

Japan's capital, Edo/Tokyo, is located in Musashi province, which was later broken into Saitama, Tokyo, and part of Kanagawa prefecture. It is not surprising that many regional rail companies and lines would be built in this relatively large area, and that many based their names on Musashi, a region of Musashi, or Musashi and another province: Musashino (two companies), Musashi-Chuo, Bushu, Jobu (two), Hokubu, Seibu-Kido, Seibu, Nanbu, Tobu, Kobu, Sobu (two), and Sobu-Nagareyama. Also, many station names include Musashi or Bushu.

\section{Tokyo Prefecture}

Many commuter railroads radiating from the city of Tokyo use the prefecture/city name in their company and mainline names. As indicated in Table 2, most of these can be considered city-based rather than specifically prefecture-based. There have been slightly more Tokyo-based company and line names than Musashi-based company and line names. (Table 1 does not include all variations of Seibu, so an exact count cannot be made from it.) However, the geographic scope covered by Tokyo companies and lines is much less. Few stations have had names based on Tokyo.

\section{Saitama Prefecture}

Saitama prefecture's name has been part of only two rail lines (Saikyo and Saitama Shuttle). A new line under construction will use its name (Saitama Kosoku). No station names are based on Saitama, though there are several based on its capital Urawa.

\section{Sagami Province}

The Sagami company (abbreviated as Sotetsu) built the Sagami line, later acquired the Jinchu line, sold the Sagami line to the national railways, and renamed the Jinchu line as its Sotetsu mainline. The Keio company's Sagamihara line is named after a city that incorporates the province name as part of the city name. Many stations on various lines include Sagami in the station name. The Zuso company's name was based on Izu and Sagami provinces, but it never had a line in Sagami when the company name was Zuso. When the Daiyuzan line (the only one in Sagami province) became part of this company, the company name was based on Suruga and Izu provinces (Sunzu); it was later changed to Izu-Hakone. 


\section{Kanagawa Prefecture}

One passenger rail company and line (Jinchu) and one freight line (Kanagawa-Rinkai) have Kanagawa-based names. Stations named Kanagawa were named after the town rather than the prefecture itself. There are several historical stations with Yokohama in their names (due to shifting of the location of the main Yokohama station). The Yokohama company built the Yokohama line, and Yokohama city operates two subway lines.

\section{Awa/Kazusa/Shimosa Provinces}

These three provinces became Chiba prefecture. There are many companies and lines with names based on one or more of the provinces or the former combined province Fusa: Boso, Uchibo, Sotobo, Hokuso, Hokuso-Kaihatsu, Sobu (two companies), Sobu-Nagareyama, Joso, and Joso-Tsukuba. Many stations include Kazusa in their names, some include Awa, and some include Shimosa or Fusa (the latter with two station names derived from a subarea, Fusamoto, as discussed earlier).

\section{Chiba Prefecture}

Several companies and lines have Chibabased names (Chiba-Kenei, Chiba, Chiba-Kyuko, Chiba Monorail, Keiyo, Keiyo-Rinkai). Lines serving Chiba city are probably named after the capital rather than the prefecture. Most serving other parts of Chiba were first built by the prefectural government; their individual line names do not include Chiba. Only a few stations have Chiba-based names; all of these can be considered city-based.

\section{Hitachi Province}

Several companies and lines have names based on Hitachi province (Johoku, Joso, JosoTsukuba, Joban, and, briefly, Joyo). The Johoku line was later renamed the Hitachi line, after the city Hitachi (written with different kanji than the province). Many stations use Hitachi as a prefix (using the province's kanji), and one uses Johoku (from the company). Hitachi station itself naturally uses the city's kanji, so it is not treated as province-based.

\section{Ibaraki Prefecture}

One former company and line was called Ibaraki; it later merged with two other companies to form Ibaraki-Kotsu. No Kanto-area stations use the name Ibaraki. There are several stations named after Mito, the prefectural capital. Three companies and lines used the name Mito: a company/line from Oyama to Mito, a line from Mito northward (with a branch) that has now become the Suigun (Mitoto-Koriyama) line, and a line from Mito southward (which temporarily was renamed Joyo one year before it closed).

\section{Kozuke/Shimotsuke Provinces}

These two provinces became Gunma and Tochigi prefectures. Many company and line names are based on these provinces: Ryomo, Jomo-Basha, Jomo, Kozuke/Joshin, Joshu, Joetsu, Tojo, Shimotsuke, and Yashu. Several stations have province-based names.

\section{Gunma/Tochigi Prefectures}

Only one line had a name based on one of these prefectures (the Gunma horsecar line, later renamed Takasaki light rail). Only a few stations use the prefecture names (two for Gunma, and two for Tochigi; strictly speaking, the latter two are city-based). Several stations are capital-based, for Maebashi and Utsunomiya. One company and line had a name based on Maebashi, and several for Utsunomiya.

In summary, many rail names were based on Musashi province, Tokyo prefecture/city, Chiba prefecture/city, and the other provinces (Sagami, Awa, Kazusa, Shimosa, Hitachi, Shimotsuke, and Kozuke). Very few were based on the remaining prefectures (Kanagawa, Saitama, Ibaraki, Tochigi, and Gunma).

\section{General Assessment and Conclusions}

This mapping and analysis project has shown that the eight former provinces in the Kanto region (Musashi, Sagami, Awa, Kazusa, Shimosa, Hitachi, Shimotsuke, and Kozuke) have had a significantly larger impact on the names of rail companies, lines, and stations 
than have the current seven prefectures (Tokyo, Saitama, Kanagawa, Chiba, Ibaraki, Tochigi, and Gunma). The difference is the greatest for station names, followed by line names, then company names. The provincebased names are much more extensively and widely dispersed throughout the Kanto region, whereas the prefecture-based names (including those that come from capital cities with the same name as the prefecture) are much more concentrated in and around Tokyo.

Analysis of the timelines for rail company names and rail line names revealed that province-based company names dominated for the first 100 years after 1872, and then in the 1970s were surpassed by prefecture/capital-based company names (but only if the latter two are treated as one category). For line names, province-based names have been greater than prefecture-based names for the entire history of Kanto rail lines, though the gap has almost been closed during the 1980s and 1990s (again, only if prefecture and capital are combined). If the analysis is extended beyond 1995, two new Tokyo-derived companies would be added (Tokyo-Rinkai-Kosoku company with its Rinkai-Fuku-Toshin line, and Toyo-Kosoku company/line.)

There are many province-based station names, including some new ones such as Hitachi-no-Ushiku (which opened on the Joban line in 1998 and thus is not included in these maps). There are very few prefecture-based station names. Even if we also consider stations that include a prefecture-based company name, there still are many more province-based station names.

The broader historical context helps explain these spatial and temporal patterns for rail company, line, and station names. The configuration, names, and overall boundaries of prefectures were not stabilized in the Kanto region until 1893, twenty-one years after the first railway line was opened. It is therefore not surprising that prefecture-based names did not become popular right away in the late-1800s. It was not yet clear exactly what the prefectures would be. However, even long after the prefectures were finalized, many rail companies continued to choose province-based names for the company name, line names, and station names. The pattern continued well into the 1900 s, though prefecture/capital-based names also gradually increased, especially with Tokyo-based names for commuter lines.

Furthermore, because many Japanese prefectures use the same name as the town or city that became the capital, it became common to continue to use the province names for the surrounding area even though the names had been officially replaced. The alternative is to use the suffix "-ken" (or "-to" for Tokyo-to) to refer to the prefecture rather than the capital city; however, including the suffix in a rail name would have made it too complex, especially if the company or line name needed to combine two place names (e.g., Tokyo-to to Chibaken). Thus, an easier solution was to continue to use province names, or to use capital-based names.

The broad distribution of province-based rail names throughout the Kanto region reflects the relatively early establishment of regional lines outward from Tokyo to other areas in Musashi and to other provinces, as well as lines between other provinces. The concentration of prefecture/capital-based names in and around Tokyo itself reflects the later development of Tokyocentric commuter lines, augmenting the Musashi-centric regional lines (which also now serve as commuter lines).

Clearly, from the standpoint of what to name a railroad company, a railroad line, or a railroad station, the provinces have lived on in Japanese perception long after their official replacement by prefectures.

\section{Acknowledgments}

This paper is an expansion of one component of the "GIS spatial history of Tokyo" that I created for my $\mathrm{PhD}$ dissertation in Urban Design and Planning at the University of Washington in 1997. The dissertation was partially funded by a one-year Hall Ammerer WRF Interdisciplinary Dissertation Research Fellowship. Acquisition of additional historical maps and other data sources in 1998 was partially funded by a University of Akron Faculty Summer Research Fellowship.

I wish to thank Mr. Yota Kumaki of the Geographical Survey Institute of Japan for his assistance in obtaining reproductions of historical topographic 
maps. My friend Mr. Tomiya Okura of Ome Folklore Museum assisted in confirming the meaning of several rail company names and supplied source materials on Saitama rail history. I also thank the many rail companies that responded to my requests for information. Finally, I am particularly indebted to several anonymous reviewers for helpful suggestions and clarifications.

I have made every effort to make this analysis accurate and complete, based on a wide variety of records. However, there may still be errors of omission or commission. I would be pleased to be informed of any corrections - as well as additions of other rail companies, lines, stations, and their name histories-by anyone who can provide suitable historical documentation.

I would especially like information about station name changes for the following abandoned lines: Gunma-Basha, Honjo, Ikaho, Isumi, Jomo-Basha, Joto, Kawagoe-Denki, Kujukuri, Musashi-Chuo, Nikko, Odawara-Basha, Oshi-Basha/Gyoda-Basha, Seibu (Shinjuku to Ogikubo), Senju-Basha, Tamagawa, Yachimata, Yaita, Yashu/Utsunomiya/Oya, and Yokaichiba. (For many of these, I have information on station locations but not name changes.)

(Received Mar. 19, 1994)

(Accepted Oct. 10, 1999)

\section{References}

Bureau of Statistics. 1903-1995. Population censuses of Japan. Tokyo: Bureau of Statistics, Office of the Prime Minister.

Chiba Urban Monorail. 1994. Townliner: Chiba urban monorail. Chiba, Japan: Chiba Urban Monorail. (JE)

Eidan. 1994. '94 eidan chikatetsu handobukku. Tokyo: Teito Kosokudo Kotsu Eidan. (J)

Enoshima Dentetsu. 1994. Written correspondence from Enoshima Dentetsu.

Hagiwara, T. 1964. Nihon no tetsudo. Osaka: Hoikusha. $(\mathrm{J})$

Hakone Tozan Tetsudo. 1988. Gurafu 100 subarashii hakone: Hakone tozan tetsudo sogyo 100-shunen kinen. Odawara, Japan: Hakone Tozan Tetsudo. $(\mathrm{J})$

Hanaue, Y., and Yasuda, O. 1981. Nihon no shitetsu, 10: Tobu. Osaka: Hoikusha. (J)

Hokuso Kaihatsu Tetsudo. 1994. Hokuso kaihatsu tetsudo: Kaisha annai. Kamagaya, Japan: Hokuso Kaihatsu Tetsudo. (J)

Ibaraki Kotsu. 1994. Written correspondence from Ibaraki Kotsu.

Ikeda, S., and Muraishi, T., eds. 1978. Kokutetsu zen-eki ruutsu daijiten. Tokyo: Takeshobo. $(\mathrm{J})$

Ikegami, A., Kitahara, M., Saito, A., and Tanaka, G., eds. 1993. Zukai koko nihonshi. Tokyo: Hitotsubashi Shuppan.

Inoue, H., and JRR. 1987. Tokyo no densha. Osaka:
Hoikusha. (J)

Inoue, H., and Takahashi, S. 1982a. Nihon no shitetsu, 17: Kita-kanto, tohoku, hokkaido. Osaka: Hoikusha. $(\mathrm{J})$

Inoue, H., and Takahashi, S. 1982b. Nihon no shitetsu, 19: Minami-kanto, koshinetsu. Osaka: Hoikusha. (J)

Ishizuka, H., and Ishida, Y. 1988. Tokyo, the metropolis of Japan and its urban development. In Tokyo: Urban growth and planning, 1868-1988 (pp. 3-35). Tokyo: Center for Urban Studies, Tokyo Metropolitan University.

Isumi Tetsudo. 1995. Written correspondence from Isumi Tetsudo. $(\mathrm{J})$

Izu Kyuko. 1992. Izu to tomo ni ikiru: izukyu 30nenshi. Tokyo: Izu Kyuko. (J)

Jomo Tetsudo. 1995. Written correspondence from Jomo Tetsudo. (J)

JRR, Miyake, Y., Kekke, Y., and Maeda, A., eds. 1991. $J R$ zensen zeneki. Tokyo: Kosai Shuppansha. (J)

JTB. 1985. Nihon kokuyu tetsudo teishajo ichiran. Tokyo: Nihon Kotsu Kosha. (J)

Keihin Kyuko Dentetsu. 1994. Keikyu handbook '94'95. Tokyo: Keihin Kyuko Dentetsu. (J)

Keio Teito Dentetsu. 1994. Keio 94 kaisha yoran. Tama, Japan: Keio Teito Dentetsu. (J)

Keisei Dentetsu. 1994. Keisei '94 kaisha yoran. Tokyo: Keisei Dentetsu. (J)

Kodama, Y. 1989. Hyojun nihonshi chizu. Tokyo: Yoshikawa Kobunkan. (J)

Kokudo Chiri-in. 1900s-1990s. $1: 200,000$ and 1: 50,000 topographic maps of Kanto area produced by Geographical Survey Institute of Japan. (J)

Kubota, H. 1977. Nihon no densha: Kosoku densha. Osaka: Hoikusha. (J)

Masai, Y., ed. 1986. Atorasu tokyo: Chizu de yomu edo 〜 tokyo/Atlas Tokyo: Edo/Tokyo through maps. Tokyo: Heibonsha. (JE)

Miyata, M. 1981. Nihon no shitetsu, 8: Tokyu. Osaka: Hoikusha. (J)

Odakyu Dentetsu. 1994. 1994 odakyu dentetsu kaisha yoran. Tokyo: Odakyu Dentetsu. (J)

Oikawa, Y. 1989. Shinpen saitama kenshi. Urawa, Japan: Saitama Prefectural Government. (J)

Ono, F. 1971. Saitama-ken no rekishi. Tokyo: Yamakawa Shuppansha. (J)

Ota, T., ed. 1995. Bakumatsu iko shi-cho-son mei hensen keitozu soran. Tokyo: Toyoshorin. $(\mathrm{J})$

Papinot, E. 1910 [1972]. Historical and geographical dictionary of Japan. Yokohama: Kelly \& Walsh. Reprinted at Rutland, VT, and Tokyo: Charles E. Tuttle.

Sagami Tetsudo. 1994. Sotetsu '94: '94 sotetsu yoran. Yokohama: Sagami Tetsudo. (J)

Saitama New Urban Transit. n.d. New shuttle in Saitama: Guideway transit system. Ina-machi, Saitama, Japan: Saitama New Urban Transit. (JE)

[Saitama] Saitama Prefectural Museum, eds. 1999. Saitama no tetsudo. Omiya, Japan: Saitama Prefectural Museum. (J) 
Seibu Tetsudo. 1994. Seibu tetsudo '94-'95 kaisha yoran. Tokorozawa, Japan: Seibu Tetsudo. (J)

Shin-Keisei Dentetsu. 1978. Shin-keisei dentetsu: Soritsu 30-nen kinen. Tokyo: Diamond. (J)

Shin-Keisei Dentetsu. 1994. Shin-keisei dentetsu '94 kaisha yoran. Kamagaya, Japan: Shin-Keisei Dentetsu. (J)

Shogakukan. 1996. Nihon chimei dai-jiten: rando japonica. Tokyo: Shogakukan. (J)

Shonan Monorail. 1994. Written correspondence from Shonan Monorail. (J)

Siebert, Loren. 1997. Creating a GIS spatial history of Tokyo. PhD dissertation. Seattle: Department of Urban Design and Planning, University of Washington.

Teito Rapid Transit Authority. 1993. Tokyo TRTA subways: Developments over the past 50 years and the situation in 1992. Tokyo: Teito Rapid Transit Authority.

Takeuchi, R., and Kadokawa Nihon Chimei Dai-Jiten Hensan Iinkai, eds. 1978. Kadokawa nihon chimei dai-jiten, Volumes 11-14 (Saitama, Chiba, Tokyo, Kanagawa). Tokyo: Kadokawa Shoten. (J)

[Tetsudo-100] Tetsudo Hyakunen Ryakushi Hensan Inkai, eds. 1972. Tetsudo hyakunen ryakushi. Tokyo: Tetsudo Tosho Kankokai. (J)
TMG Planning Bureau. 1989. Tokyo no toshi-keikaku hyakunenshi. Tokyo: Planning Bureau, Tokyo Metropolitan Government. (J)

TMG Transportation Bureau. '94 toei kotsu no aramashi. Tokyo: Transportation Bureau, Tokyo Metropolitan Government. (JE)

Tobu Tetsudo. 1994. '94 tobu kaisha yoran. Tokyo: Tobu Tetsudo. (J)

Tokyo Kyuko Dentetsu. 1994. '94-'95 tokyo kyuko. Tokyo: Tokyo Kyuko Dentetsu. (J)

Tokyo Monorail. n.d. Tokyo monoreru kaisha annai Tokyo: Tokyo Monorail. (J)

Yamaman. n.d. Shin-kotsu shisutemu: Yukarigaokasen. Tokyo: Yamaman. (J)

Yokohama Roads Bureau. 1994. Seaside line: Shinkotsu shisutemu kanazawa seaside line. Yokohama: Roads Bureau, City of Yokohama. (J)

Yokohama Transportation Bureau. 1995. Shinrai o kokoro de hakobu shi-basu, chikatetsu. Yokohama: Transportation Bureau, City of Yokohama. (JE)

Yoshida, T. 1937-1940. Dai nihon chimei jisho. Tokyo: Fuzanbo. (J)

Yoshikawa, F. 1989. Nihon densha hattatsu-shi. Osaka: Hoikusha. (J)

Yoshikawa, F. 1990. Shin-kotsu shisutemu. Osaka: Hoikusha. (J) 